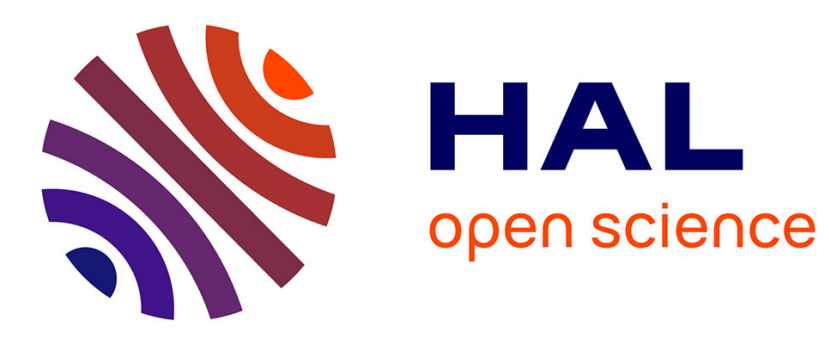

\title{
Enhanced ZnO based solar cell efficiency by piezo-phototronic effect
}

Rabeb Belghouthi, Ninel Kokanyan, Michel Aillerie

\section{To cite this version:}

Rabeb Belghouthi, Ninel Kokanyan, Michel Aillerie. Enhanced ZnO based solar cell efficiency by piezophototronic effect. Technologies and materials for renewable energy, environment and sustainability: TMREES20, Jun 2020, Athens, Greece. pp.020059, 10.1063/5.0032652 . hal-03092718

\section{HAL Id: hal-03092718 \\ https://hal.univ-lorraine.fr/hal-03092718}

Submitted on 4 May 2021

HAL is a multi-disciplinary open access archive for the deposit and dissemination of scientific research documents, whether they are published or not. The documents may come from teaching and research institutions in France or abroad, or from public or private research centers.
L'archive ouverte pluridisciplinaire HAL, est destinée au dépôt et à la diffusion de documents scientifiques de niveau recherche, publiés ou non, émanant des établissements d'enseignement et de recherche français ou étrangers, des laboratoires publics ou privés. 


\title{
Enhanced ZnO Based Solar Cell Efficiency by Piezo-Phototronic Effect
}

\author{
Rabeb Belghouthi ${ }^{1, \mathrm{a})}$, Ninel Kokanyan ${ }^{2}$, and Michel Aillerie ${ }^{2}$ \\ ${ }^{1}$ Université de Lorraine, CentraleSupélec, LMOPS, F-57000 Metz, France \\ ${ }^{2}$ CentraleSupélec, Université de Lorraine, LMOPS, F-57000 Metz, France
}

Corresponding author: rabebbelghouthi@gmail.com

\begin{abstract}
We report piezo-phototronic effects on the electrical properties of a Schottky contact metal/ZnO(n) solar cell. The piezo-phototronic effect is a three way coupling effect of piezoelectric, semiconductor and photonic properties occurring in non-central symmetric semiconductor materials when an applied strain to a semiconductor generates a piezoelectric potential controlling the carrier generation, transport, separation and/or recombination at the junction. The purpose of the present study is to determinate the influence of piezoelectric polarization on the electrical characteristics of this solar cell. Results show that the stress causes an increase of the electric field in the region where the piezoelectric fields are located. The sign of the stress proves that if it is positive (extensive strain), the effective barrier height increases which reduces the flow of electrons and thereafter is considered as a limiting factor for photovoltaic conversion, However, if the stress is negative (compression strain), a significant improvement of photovoltaic efficiency is obtained. Using the piezoelectric effects created by an external stress, our study provides not only a theoretical understanding about the piezo-phototronic effects on the characteristics of a solar cell but also assists for the possible design improvement allowing to increase.
\end{abstract}

Keywords. Piezoelectric polarization; piezo-phototronic effect; Schottky contact metal/ZnO(n); Stress; Photovoltaic Conversion

\section{INTRODUCTION}

Even if the most current commercial photovoltaic cells are based on single or multiple semi-conductor junctions, solar cells can also be realized using a single Schottky junction realized between a semiconductor and a metal. In fact, solar cells based on Metal-Semiconductor, MS, Schottky-barrier have a long history. In 1883, Charles Fritts [1], made one of the world's first solar cells by coated selenium with a thin layer of gold. Since that time, they were currently being examined for their suitability in large-scale terrestrial applications since they are significantly simpler to fabricate due to the fact that the junction is at the surface obtained with an associated lower-cost technology. Nevertheless, for the development of a solar cell technology, the consideration of the quantum efficiency is essential. In solar cell, the internal quantum efficiency, $\eta \mathrm{IQE}$, is the product of four efficiencies [2], each corresponds to a step in the charge generation process: absorption of light, diffusion to a dissociation site, charge transfer, and the charge collection efficiency. By simulation with some unusual physical conditions (as example a quantum efficiency of unity associated to a barrier height equal to the energy gap), one can expect a maximum theoretical efficiency of around $22 \%$ with a silicon based MS solar cell, being not so far that obtained with pn junctions. Nevertheless, the experimental devices never achieve efficiencies of more $10 \%$. This poor efficiency can also be analyzed considering the open circuit voltage, Voc that is very low in MS diode. It was shown that Voc is increased by the introduction in the MS diode of an interfacial layer, thus creating a Metal-Insulator Semi conductor MIS solar cell. This additional layer of few nanometers will directly affect in a positive manner the solar cell performance as it not only increases Voc, but also the transport control in the junction with the introduction of localized states for field shaping and fixed charges. Some recent researches have confirmed the 
potential commercial viability of a particular Schottky junction solar cell design based on Metal-InsulatorSemiconductor Inversion Layer, the silicon "MIS-IL solar cell", for which an increase of the efficiency is expected without any decrease of the advantage of the low cost associated to the MIS solar cell. By else, already in 1957, Henish \& al. [3] have shown the influence of a strain on the photovoltaic efficiency of Schottky solar cells. They pointed that the photovoltaic efficiency of a Schottky diode decreases with the pressure of the contact because it determines the intimacy of the interaction between the carriers of the metal and those of the semiconductor. In connection with the results above, more recently, much attention has been focused on piezoelectric semiconductor materials, such as $\mathrm{ZnO}, \mathrm{InN}$ and $\mathrm{Cds}$ for the realization of solar cells [4-14]. In the internal efficiency, occurs the charge transfer, which corresponds to a dissociation of photo-carriers into a free electron and hole pairs and strongly depends on the internal electric field. For example, in the III-nitrides, a contribution in the internal electric field due to a polarization via the creation of sheet charges can achieve values as high as $1 \mathrm{MV} / \mathrm{cm}$ [15]. Thus, based on this ascertainment, it is then possible to consider using the effects of polarization in favor of solar cell design to enhance the efficiency. The increase of the polarization will increase the carrier collection, reducing ohmic resistances and bending bands and finally the surface recombination. In the last decade, solar cells integrating piezoelectric semiconductors have demonstrated that the inner crystal piezoelectric potential can be effectively used for enhancing the charge transfer efficiency [12-18]. These effects are included in the so-called Piezo-phototronic effect, which is a three way coupling effect of piezoelectric, semiconductor and photonic properties occurring in non-central symmetric semiconductor materials: By applying a strain to a semiconductor, a piezoelectric potential is generated and then, the piezoelectricity controls the carrier generation, transport, separation and/or recombination at the junction. Following these results, polarization effects are now considered as one of the main parameters in designing performing solar cells based on piezoelectric materials.

In the present work, we report an analysis of piezo-phototronic effect, mainly the charge transport effect in Schottky-barrier solar cells with piezoelectric effects. Several parameters, influencing the solar cell efficiency, including the photocurrent and the open circuit voltage will be investigated taking into account the piezoelectric polarization.

\section{THEORETICAL FORMULATION}

Polarization can be accounted for in a semiconductor according to the following equation [18]:

$$
D=\varepsilon_{0} \varepsilon_{r} E+P
$$

Where $\mathrm{D}$ is the electric displacement, $\mathrm{E}$ is the electric field, $\mathrm{P}$ is the net polarization, which is strain-induced, and $\varepsilon_{0}$ and $\varepsilon_{\mathrm{r}}$ are the vacuum and relative permittivities, respectively. The relationship between the polarization $\mathrm{P}$ and a small form mechanical strain S is given by the Hook's law [18-20]:

$$
P_{i}=e_{i j k} S_{j k}
$$

where the third order tensor $\mathrm{e}_{\mathrm{ijk}}$ is the piezoelectric tensor. For $\mathrm{ZnO}$ grown along the $\mathrm{c}$ axis, the component of the strain is $\mathrm{S}_{33}$ and $\mathrm{P}$ is expressed as:

$$
P=-e_{33} S_{33}=q \rho_{\text {piezo }} W_{\text {piezo }}
$$

The electrostatic behavior of charges in the semiconductor is described by the Poisson equation:

$$
\nabla^{2} V=-\frac{\rho}{\varepsilon}
$$

Where $\mathrm{V}$ is the electrostatic potential, $\varepsilon$ is the permittivity of the material and $\rho$ is the density charge. In a semiconductor $\mathrm{n}$-type, the volumic charge distribution is represented by a rectangle profile with a depth equal to $\mathrm{W}_{\mathrm{Dn}}$ and a density $\mathrm{N}_{\mathrm{D}}$ as suggested in Ref. [6]. Moreover, considering the piezophototronic effect, under the action of the 
applied stress, polarization charges will appear at the metal / semiconductor interface developing in a superficial layer on the semiconductor side. Actually, the charge distribution zone is very narrow, at the surface compare to the witdth of the $\mathrm{ZnO}$ layer. Thus, the shape of this zone can be also represented by a rectangular profile close the surface that extends over a depth noted $\mathrm{W}_{\text {piezo }}$ with a density equal to $\rho_{\text {piezo. }}$. These representations are schematically illustrated in Fig. $1 . \mathrm{W}_{\text {piezo }}, \rho_{\text {piezo }}, \mathrm{W}_{\mathrm{Dn}}$ and $\mathrm{N}_{\mathrm{D}}$ are treated as the main parameters allowing optimization of the cell. The total density of charges is thus given by:

$$
\rho=\left\{\begin{array}{c}
q\left(N_{D}+\rho_{\text {piezo }}\right) \text { for } 0 \leq z \leq W_{\text {piezo }} \\
q N_{D} \text { for } W_{\text {piezo }} \leq z \leq W_{D n}
\end{array}\right.
$$

Where $\mathrm{N}_{\mathrm{D}}$ is the n-type doping concentration, $\rho_{\text {piezo }}$ is the density of polarization charges, and $\mathrm{W}_{\mathrm{Dn}}$ is the depletion layer width in the n-side. The expression of the electric field can be deduced by integrating the Eq. (4):

$$
E(z)=\left\{\begin{array}{c}
\frac{q}{\rho_{\text {piezo }}}\left(z-W_{\text {piezo }}\right)+\frac{q N_{D}}{\varepsilon}\left(W_{\text {piezo }}-W_{D n}\right) \text { for } 0 \leq z \leq W_{\text {piezo }} \\
\frac{q N_{D}}{\varepsilon}\left(z-W_{D n}\right) \text { for } W_{\text {piezo }} \leq z \leq W_{D n}
\end{array}\right.
$$

are significantly simpler to fabricate due to the fact that the junction is at the surface obtained with an associated lower-cost.

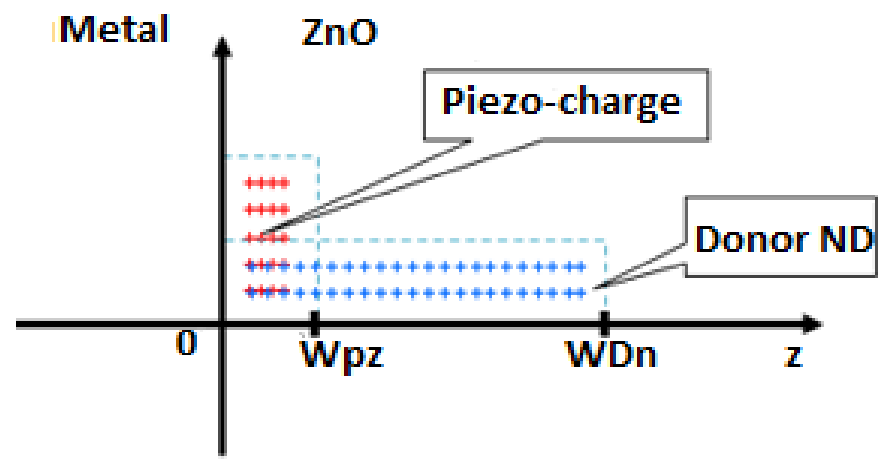

FIGURE 1. Schematic representation of piezoelectric and donor charge distribution in a metal/semiconductor interface.

The charge transport in the metal/ZnOSchottky contact is dominated by the majority carriers. The current density of an ideal Metal-Semiconductor, for piezoelectric solar cells, is given has the form:

$$
J=J_{s a t}\left[\exp \left(\frac{V}{V_{t h}}\right)-1\right]-J_{p h}
$$

Where $\mathrm{V}_{\mathrm{th}}$ is the thermal voltage, $\mathrm{J}_{\mathrm{ph}}$ is the photocurrent density and Jsat represents the saturation current density given by:

$$
J_{\text {sat }}=k \exp \left(-\frac{\varphi B_{n 0}}{V_{t h}}\right) \exp \left[\frac{q \rho_{\text {piezo }} W_{\text {piezo }}{ }^{2}}{2 \varepsilon V_{\text {th }}}\right]
$$

with 


$$
k=\frac{q D_{n} N_{c}}{V_{t h}} \sqrt{2 q N_{D}\left(\psi_{B i o}-V\right) / \varepsilon}
$$

Where $\mathrm{q}$ is the electronic charge, Dn is the electron diffusion coefficient, $\mathrm{Nc}$ is the effective density of states in the conduction band, $\Psi$ Bio and $\varphi B_{n 0}$ are the built-in potential and Schottky barrier height without piezoelectric charges. As shown in Eq.(8), an additive potential due to the applied strain is added at the barrier $\varphi B_{n 0}$. An effective barrier potential can be defined from the Schottky barrier height without piezoelectric charges $\varphi B_{n 0}$ and the mechanical strain $\mathrm{S}_{33}$ by using the following relationships:

$$
\varphi_{\text {effB }}=\frac{2 \varepsilon \varphi B_{n 0}+q e_{33} S_{33} W_{\text {piezo }}}{2 \varepsilon}
$$

By setting $\mathrm{J}=0$, the open circuit voltage of a metal- $\mathrm{ZnO}$ solar cell can be calculated as follows:

$$
V_{o c}=V_{t h}\left\{\ln \left(\frac{J_{p h}}{J_{s a t}}\right)+\frac{q \rho_{\text {piezo }} W_{\text {piezo }}^{2}}{2 \varepsilon_{s} V_{\text {th }}}\right\}
$$

The characteristics of the solar cell are calculated using the typical material constants, among anothers, the piezoelectric constant, $\mathrm{e}_{33}=1.22 \mathrm{C} / \mathrm{m} 2$ and the relative dielectric constant, $\varepsilon \mathrm{s}=8.91$ [6]. The width of the piezoelectric charge profile is taken as $\mathrm{W}_{\text {piezo }}=0.25 \mathrm{~nm}$. The simulation are performed at local lattice temperature $\mathrm{T}=300 \mathrm{~K}$.

\section{RESULTS AND DISCUSSION}

Figure 2 shows the electric field as function of the width of the $\mathrm{ZnO}$ layer and the piezoelectric charge density. The depletion region width varies from 0 to $1 \mathrm{~nm}$. As showing in this graph, there is an increase of the electric field in the region where the piezoelectric charges are located. The exceeded loads due to the stress cause the increase of the internal electric field near the interface of the metal / $\mathrm{ZnO}$ semiconductor junction. When the density of piezoelectric charges is significant enough, the internal electric field increases. As is also shown, the field is strong when the piezoelectric charges are high and the width of depletion region is very small.

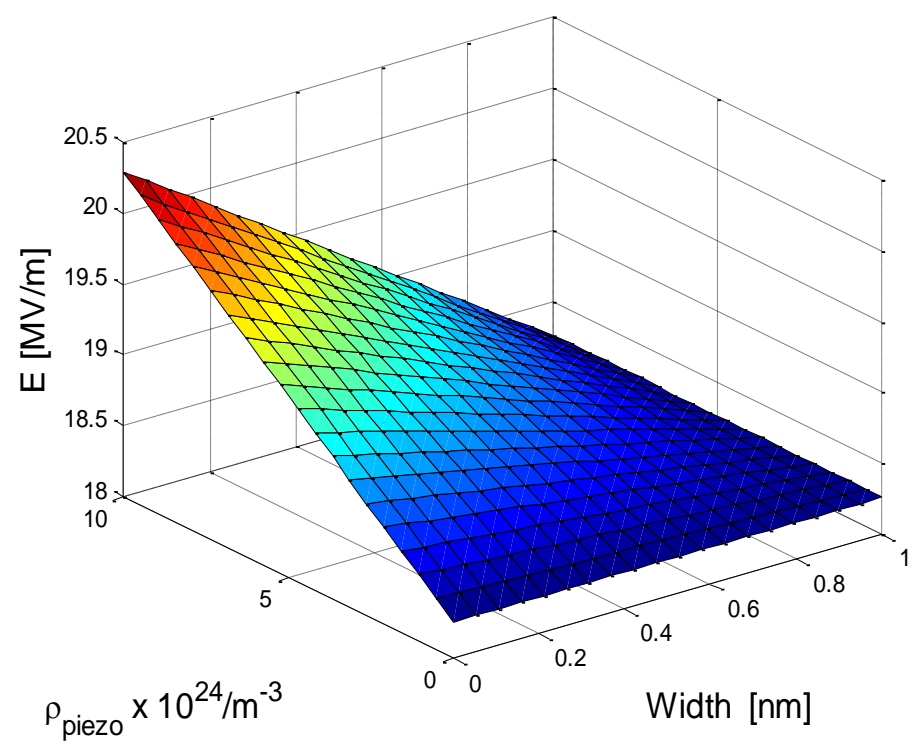

FIGURE 2. The electric field at the surface and the width of depletion region as a function of the piezoelectric charge densities. 
The effective barrier as a function of strain in the interval $[-1,1]$ is shown in Fig. 3. For compression strain $\left(\mathrm{S}_{33}\right)$, the height of the effective barrier increases, thus limiting the efficiency of the photovoltaic conversion. To better understand the effect of the strain on the electrical characteristics of the strained Metal-ZnO solar cell, we plotted in, Fig. 4, the saturation current density as a function of the strain $\mathrm{S}_{33}$.

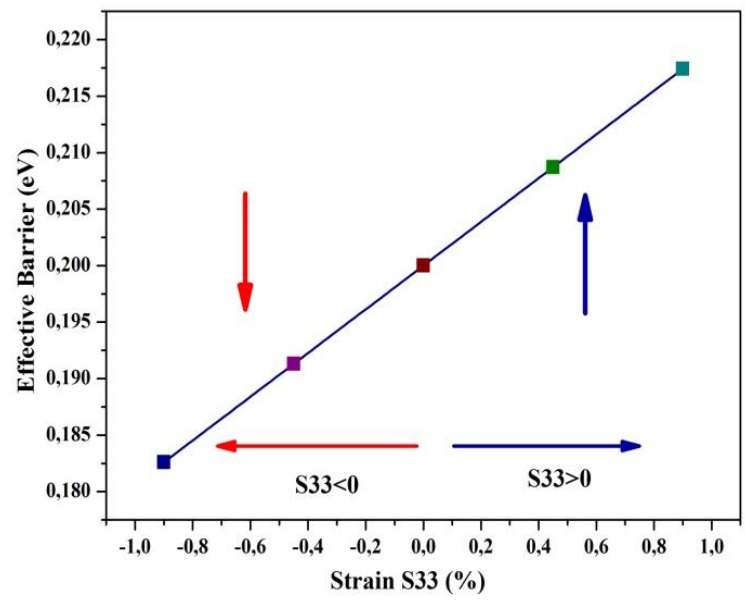

FIGURE 3. Effective barrier of a $\mathrm{M}-\mathrm{ZnO}$ solar cell under various strains.

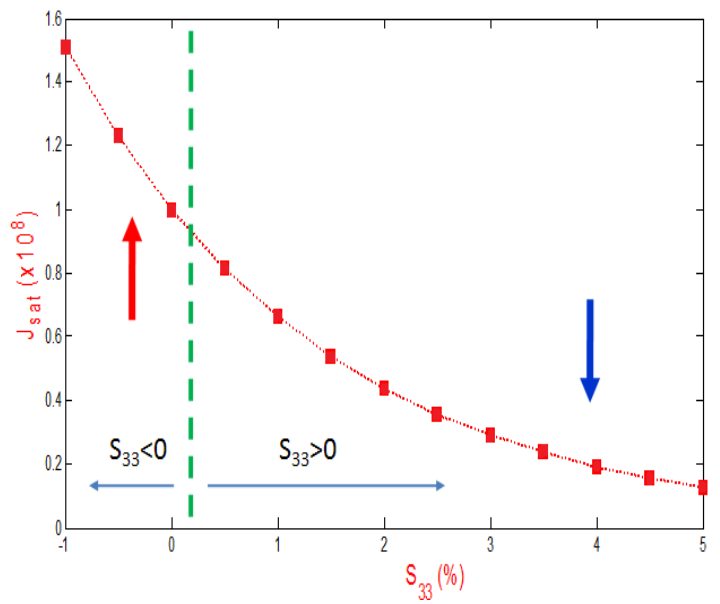

FIGURE 4. Saturation current density of a M-S solar cell as a function of the strains $S_{33}$. 


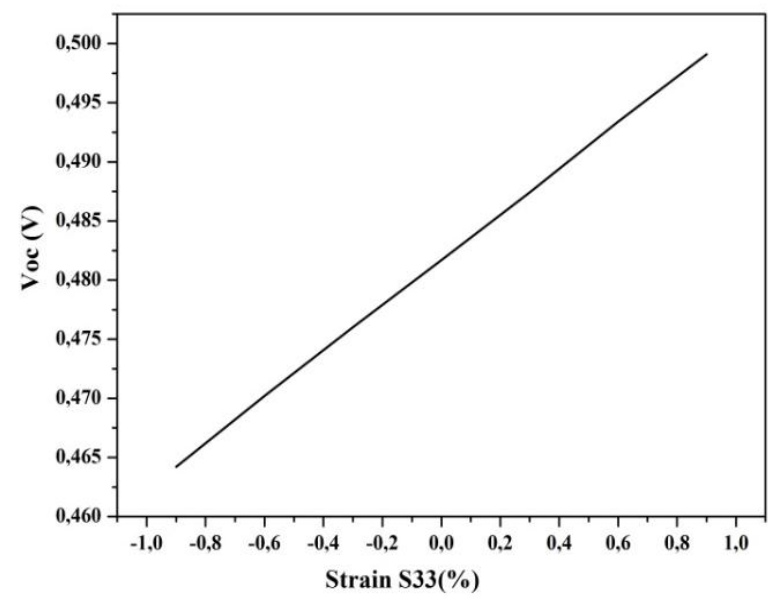

FIGURE 5. Open circuit voltage of a $\mathrm{M}-\mathrm{ZnO}$ solar cell for different applied strains

As shown in Fig. 4, we note that the saturation current decreases when the strain increases from negative to positive values and, as shown in Fig. 5, induces an increase of the open-circuit voltage. Moreover, the J-V characteristics of a $\mathrm{M}-\mathrm{ZnO}$ solar cell under different strains applied at fixed photocurrent density is reported in Fig 6.

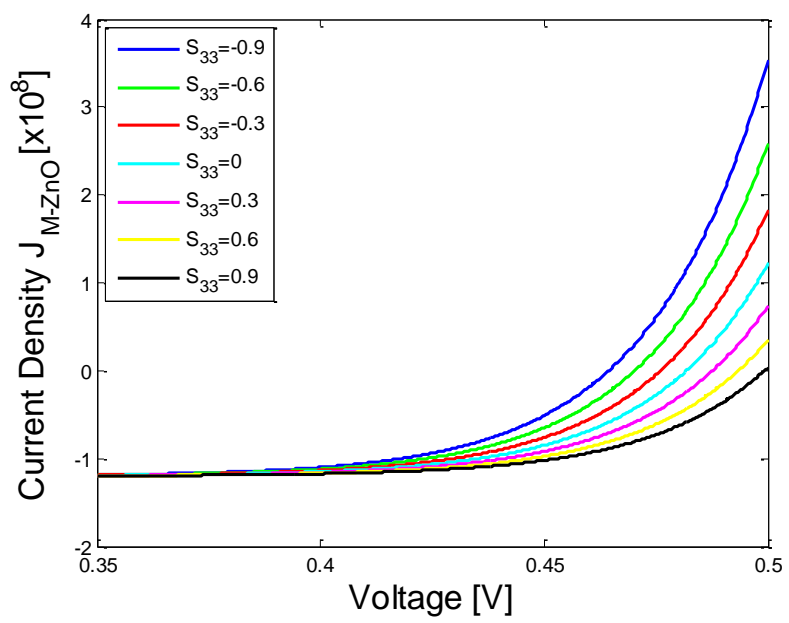

FIGURE 6. Current-Voltage characteristics of a M-S solar cell for different applied strains.

We note that the increase of Jsat produces a reduction of $\mathrm{V}_{\mathrm{OC}}$ proportional to $\log$ (Jph/Jsat). This result is in good agreement with the behavior of the Schottky barrier. Consequently, the fill factor of M-S solar cells finally decreases with the stress. The decrease of the saturation current density produces the increase of the fill factor, which can be considered as a positive effect for the photovoltaic conversion. At this stage, we can conclude that the current density as well as the open-circuit voltage can be controlled not only by the magnitude of the strain but also by its sign (tensile, compression).

Finally, the output power of the piezoelectric $\mathrm{M}-\mathrm{ZnO}$ solar cell can be obtained from the product of the current and the voltage. Fig. 7 shows the output power as a function of voltage for different strain values. 


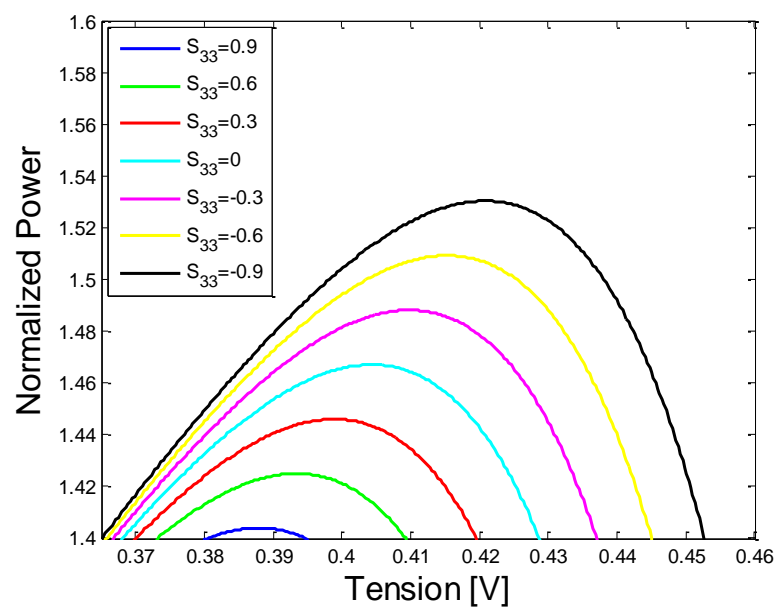

FIGURE 7. Output power of $\mathrm{M}-\mathrm{ZnO}$ solar cell as a function of voltage for different applied strains.

\section{CONCLUSION}

In summary, we have investigated the characteristics of a strained photovoltaic Shottky contact metal/ZnO(n) PV solar cell and analysed the piezo-phototronic effect generated in the junction when an applied strain is applied on the PV cell. For this structure, the piezoelectric effects are supposed created by mechanical stress applied from outside. We clearly point out that the increase of saturation current Jsat in the cell produces a reduction of open-circuit voltage $\mathrm{V}_{\mathrm{OC}}$ proportional to $\log (\mathrm{Jph} / \mathrm{Jsat}$ ), with Jph the photocurrent. It was also evidenced that, within normalized experimental conditions $\left(\mathrm{AM} 1.5, \mathrm{~T}^{\circ}=300 \mathrm{~K}\right)$ a positive stress applied on the cell increases the available output power of the cell whereas a negative one decrease this power. When applying an experimentally usual stress, S33 = 0.9 , the gain in power is above $4 \%$, mainly due tot the increase of the voltage corresponding to the maximum power point. This study has the advantage to show the positive effects of stress, which can improve the photovoltaic efficiency of a solar cell. Also, it assists the design of high performant solar cells.

\section{REFERENCES}

1. L.M. Fraas, "History of Solar Cell Development," Low-Cost Solar Electric Power, 1-12, 2014.

2. P. Peumans, A. Yakimov, and S.R. Forrest, "Small molecular weight organic thin-film photodetectors and solar cells," J. Appl. Phys. 93, p.3693, 2003.

3. H. K. Henisch and C. Popescu, "Contacts with semi-insulators," Nature 257,363-367, 1975.

4. G. Zhu, A. C. Wang, Y. Liu, Y.Zhou, and Z. L. Wang, "Functional Electrical Stimulation by Nanogenerator with 58 V Output Voltage," Nano Lett. 2012.

5. Ambacher, "O. "Growth and applications of Group III-nitrides," Journal of Physics D: Applied Physics, 31, 20, 2653-2710, 1998.

6. Y. Yhang, Y. L. Zhong L. Wang, "Fundamental Theory of Piezotronics," Adv. Mater, XX, 1- 10, 2011.

7. J. Zhou, P. Fei, Y.D. Gu, W.J. Mai, Y.F. Gao, R. Yang, G. Bao, Z.L. Wang, "Flexible piezotronic strain sensor," Nano Lett, 8, 3973, 2008.

8. Y. Yang, J. Qi, W. Guo J. Zhao, X. Wang, and Y. Zhang "Size dependence of transverse electric transport in single ZnO nanoneedles," Appl. Phys. Lett, 96, 152101, 2010.

9. Q. Yang, W. Wang, S. Xu, and Z. L. Wang, "Enhancing Light Emission of ZnO Microwire-Based Diodes by Piezo-Phototronic Effect," Nano Lett, 11 (9), pp 4012-4017, 2011.

10. Y. F. Hu, Y. Zhang, Y. L. Chang, R. L. Snyder and Z. L. Wang, "Optimizing the power output of a ZnO photocell by piezopotential, " ACS Nano, 4, 4220-4224, 2010.

11. Y. Yang, W. Guo, Y. Zhang, Y. Ding, X. Wang and Z. L. Wang, "Piezotronic Effect on the Output Voltage of P3HT/ZnO Micro/Nanowire Heterojunction Solar Cells," Nano Lett, 11, 4812-4817,2011.

12. R. Belghouthi, S. Taamalli, F. Echouchene, H. Mejri, H. Belmabrouk, "Modeling of polarization charge in Nface InGaN/GaN MQW solar cells," Materials Science in semiconductor Processing. 40,424-428 , 2015. 
13. R. Belghouthi, J.P. Salvestrini, M.H. Gazzeh and C. Chevalier, "Analytical modeling of polarization effects in InGaN double hetero-junction p-i-n solar cells," Superlattices and Microstructures.100, 168-178, 2016.

14. R. Belghouthi, T. Selmi, H. Belmabrouk, Design and Modeling of Mechanical Systems -III, 1-9, 2017.

15. R. Belghouthi ,M. Aillerie, A. Rached, H. Mejri, "Effect of temperature on electronic and electrical behavior of InGaN double hetero-junction p-i-n solar cells," Journal of Materials Science Materials in Electronics, 30, 4 , 4231-4237,2019.

16. Y. Zhang, Y. Yang and Z. L. Wang, "Piezo-phototronics effect on nano/microwire solar cells,"Energy Environ.Sci.,5, 6850,2012.

17. X. Wen, W. Wu, Z.L. Wang, “ Effective piezo-phototronic enhancement of solar cell performance by tuning material properties," Nano Energy 2, 1093-1100, 2013.

18. T. Ikeda, "Fundamentals of piezoelectricity, Oxford University Press, Oxford UK, 1996.

19. S.M.Sze, "Physics of semiconductor Devices," Wiley, New York, 1981.

20. G. A. Maugin," Continum Mechanics of Electromagnetic solids, " North-Holland, Amsterdam,1988. 